\title{
Study on Prevalence of Diarrhea among Children with Special Reference to Rotavirus in Thanjavur, Tamilnadu, India
}

\author{
A. Shanthi ${ }^{1^{*}}$ and C.K. Bhuvaneshwari ${ }^{2}$ \\ Department of Microbiology, Thanjavur Medical College, Thanjavur-613004, \\ Tamilnadu, India \\ *Corresponding author
}

\section{Keywords \\ Diarrhoea, \\ Rotavirus, \\ Gasteroentritis, \\ Thanjavur \\ Article Info \\ Accepted: \\ 10 January 2019 \\ Available Online: \\ 10 February 2019}

A B S T R A C T

Diarrhoeal diseases are the second most common cause for mortality in children below 5 years of age. Life threatening gasteroentritis in children are most commonly caused by Rotavirus infection. Worldwide, more than half a million children under the age of five years die each year due to diarrhea. In 2013, an estimated 215,000 of these deaths were due to Rotavirus, with more than $90 \%$ occurring in developing countries. Rotavirus is the cause of $23-39 \%$ of diarrhoea in children. A rotavirus infection usually starts with a fever and vomiting, followed by 3-8 days of watery diarrhea. The infection can cause abdominal pain as well. Prevalence of rotavirus infection varies according to age, season and geographical area. The aim of this study is to determine the prevalence of rotavirus and to provide useful epidemiological and clinical data for rotavirus surveillance. About 80 children who are all diagnosed as having acute gastro enteritis and admitted in the pediatric ward were included in this study. This study was done over a period of one year from July 2014 to June 2015.In this study youngest child was one month old and oldest child was 4 years 10 months old. More than $80 \%$ of RVGE cases were identified to be under two years of age in Thanjavur district and also it is most prevalent in the winter months with common symptoms of diarrhoea and vomiting. This was the First study using Rota antigen ELISA test for Serological diagnosis of rotavirus in Thanjavur medical college and hospital for 80 samples.

\section{Introduction}

Gastroenteritis is a common illness which can be particularly serious in young children. No specific antiviral treatment is available and antibiotics are not effective. Life threatening gasteroentritis in children are most commonly caused by Rotavirus infection. A Rotavirus infection usually starts with a fever and vomiting, followed by three to eight days of watery diarrhea. The infection can cause abdominal pain as well. Diarrhoea is major symptom of Rotavirus infection. Villi of the small intestine are infected by Rotaviruses. They multiply in the cytoplasm of enterocytes and damage their transport mechanisms. The mechanism of pathogenesis behind diarrhoea were (a) Reduction in total small intestinal surface area due to cell lysis, leading to a decrease in net fluid absorption (primary 
malabsorption) and lead to villous atrophy, (b) changes in the osmotic permeability of the mucosa secondary to cellular destruction, transepithelial resistance is decreased after Rotavirus infection result in increased epithelial permeability (Obert et al., 2000). In young children Intestinal permeability has also been investigated using polyethylene glycols (PEGs). In acute phase of virus infection PEG absorption was significantly lower than during 3 to 5 weeks after infection, (Stintzing et al., 1986) (c) Increased electrolyte secretion due to reactive crypt cell hyperplasia (Salim et al., 1995). Diarrhoea caused by Rotaviruses may be due to impaired sodium and glucose absorption as damaged cells on villi are replaced by nonabsorbent immature crypt cells. Another theory was enzyme lactase which is normally present in the lysozymes and in the brush border of intestinal villi. This enzyme in upper small intestine hydrolyzes the Lactose. When Rotavirus infects these cells which get damaged leads transient lactase deficiency. This pathogenesis cause increase in osmotic activity, increase in intestinal fluid, and causes bloating, distension, cramps, and finally watery diarrhoea. As the infected individuals had secondary lactose intolerance, sugar can be demonstrated in the stools (Ashwin Borade, 2010). The major determinant of RNA segment responsible for pathogenesis is VP4. The other genes responsible for pathogenesis are VP3, VP7, NSP1, NSP2, and NSP4.48 49 NSP4 acts as enterotoxin considered as one of the important causes for pathogenesis of Rotavirus infection (Ball et al., 1996). Signal transduction pathway is triggered which induces secretion. Into the lumen of the intestine damaged cells form slough and release large quantities of virus, which appear in the stool (up to 1012 particles per gram of faeces). Viral excretion usually lasts from 2 to 12 days. Intestine restores its normal function only after 3 to 8 weeks.
Rota virus replication occurs exclusively in cytoplasm of mature epithelial cell (i.e.) differentiated enterocytes at the tips of vili of the small intestine. In vitro replication was studied in secondary monkey kidney cells and in immortalized monkey kidney cell lines (MA104, BS-C1) were there was similar replication as in humans (Estes and Cohen, 1989).

Rotaviruses are very contagious. They are generally transmitted by fecal-oral route. Also transmitted by respiratory route but it is not usual mode of spread. Duration of spread of virus from the stool is from 4-25 days of infection. Transmission is very efficient as these viruses are resistant to physical inactivation. The rapid spread of the infection is due to its ability to survive on various surfaces under different conditions. Recently there are speculations about role of animals as source of Rotavirus infection in humans. Human - bovine reassortant strains, human porcine reassortant strains, human-simian reassortant strains have been endemic in India (Estes et al., 2013). Rotavirus plays a role in causing Nosocomial diarrhoea in children less than 5 years, it constitutes about $18 \%$ of Nosocomial diarrhea (Alrifai et al., 2009). Major risk factor in the incidence of AGE was considered to be Poor sanitation.

The most effective method to prevent and to reduce Rotaviral disease burden is the Vaccination. World health organization's strategic advisory group of experts (SAGE) strongly recommends including rotavirus vaccine in national immunization programme, where under 5 mortality is more than $10 \%$.

\section{Materials and Methods}

This study includes of 80 children aged less than 5 years suffering from acute gastroenteritis, admitted in pediatric ward, at tertiary care hospital Thanjavur Medical 
college Hospital, Thanjavur during July 2014 to June 2015. All the 80 samples initially tested to rule out bacterial and parasite causes.

\section{Specimen collection}

About $10-15 \mathrm{ml}$ of freshly passed stool samples is collected in sterile, wide mouth, leak proof plastic container from each child under study. Stool samples should be collected within 7 days of onset of symptoms. After the collection, the stool samples were immediately transported to the laboratory for further processing. Collected specimens are stored in deep freezer at $-20^{\circ} \mathrm{C}$ until tested for Rotavirus antigen.

\section{Specimen processing}

The stool samples were immediately transported to the laboratory for further processing. Initially faecal samples are subjected to Macroscopic examination and microscopic examination for Colour, Consistency and Atypical components like mucus, blood and parasites.

Then the samples are subjected to microscopic examination by saline and iodine wet mount for RBCs, Leucocytes, and Parasitic ova and cysts.

\section{Saline wet mount}

It is prepared by mixing the stool with physiological saline. It is colorless preparation which highlights the staining property of egg, detects motility of trophozoites and other structures like pus cells, RBCs.

\section{Iodine wet mount}

It is prepared by mixing the stool with iodine. It is brown colored preparation which highlights the presence of nuclei and glycogen mass in cyst. The faecal specimens were subjected to culture in order to look for common enteropathogens. The stool sample was inoculated in MacConkey plates and incubated for 18 to 24 hours at $37^{\circ} \mathrm{C}$. At the end of the incubation period, the plates were examined for the isolates.

Bacterial isolates were identified by adopting the procedures of Gram staining, motility and routine biochemical reactions like Catalase test, oxidase test, motility test was done followed by Indole test, Methyl Red Test, Voges Proskauer Test, Citrate test, Urease test, nitrate reduction test, TSI test were done and results were recorded. Based on these tests, the organisms were identified. Quality control was also performed for all the standard tests.

\section{ELISA}

By using PremierTM Rotaclone ELISA Kit Rotavirus antigen was detected. Rota virus antigen detection was done by ELISA method. A (urea peroxide) and substrate B Tetra Methyl Benzidine (TMB) are added to the wells and incubated for 10 minutes at room temperature. The enzyme bound in the wells converts the colour-less substrate to blue colour. The intensity of the blue colour is directly proportional to the concentration of rotavirus antigen in the sample. Addition of stop solution converted the colour from blue to yellow. Wells were read spectrophotometrically using a $450 \mathrm{~nm}$ filter.

\section{Results and Discussion}

In this study the prevalence of rotavirus was $29 \%$, Table 1 and 2 . This value almost rationale with the prevalence rates of rotaviral infections in developing countries. This prevalence rate is similar to prevalence rate (28.57\%) of the study by Shetty et al., (2014) at Karnataka.Error! Bookmark not defined. 
Manohar et al., 2015, states that $25.66 \%$ of the children aged under 5 years of diarrhea are due to rotavirus. In India high prevalence were reported from Kerala (70\%) and Manipur (89\%) due to epidemiological nature of these places.

Out of 80 children in this study, majority of children belongs to 7-12 months of age (36\%). In Error! Reference source not found. 3 out of $23(29 \%)$ positive children for rotavirus antigen, $20(35 \%)$ were in the age group below 2 years and $3(13 \%)$ were in the age group above 2 years. There was a significant difference between the age group of less than 2 years and age group of more than 2 years $(\mathrm{p}<0.05)$. Under five age distribution in positive children in this study is similar to other studies in the world wide by Kurugol et al., 2003; Chavan et al., 2013 and Shetty et al., 2014. According to WHO Scientific working group 6-24 months of age is vulnerable group for RV infections,

In the present study out of 80 children 46 (58\%) were male children and $34(42 \%)$ were female children. Out of 23 (29\%) positive children, $12(26 \%)$ were male children 11 $(32 \%)$ were female children. Sex distribution in Rota virus positive and negative was almost similar. With reference to Table 2, there was no significant difference between the sexes in this study $(p>0.05)$. Zafer
Kurugol et al., (2003) stated that prevalence in both male and female children was same.Error! Bookmark not defined.

Seasonal distribution in all 80 cases as well as positive and negative cases in this study clearly states that rotavirus infection occurs throughout the year but peak infection occurs during winter months November to January. Out of 30 cases 10 were positive during October to December about $33 \%$ of prevalence during these months. Out of 12 cases 5 cases were positive during Jan March shows prevalence of $42 \%$. Totally there was high prevalence rate during winter months from October to March. There was significant difference of rotavirus prevalence between winter months and other seasons.

The clinical presentation in all 80 cases and Rota viral positive cases were showed in Error! Reference source not found.4. Diarrhoea present in all cases in this study showed $100 \%$ prevalence. $87 \%$ of RV positive children presented with vomiting which was considered as next predominant symptom. So, prevalence of vomiting was 41\%.Percentage of RV positive children presented with fever was about $74 \%$.prevalence rate for fever was $31 \%$. Decreased urine output was present in $13 \%$ of $\mathrm{RV}$ positive cases, but prevalence rate was about $100 \%$ (Table 5).

Table.1 Rotavirus antigen test by ELISA

\begin{tabular}{|c|c|c|c|}
\hline Result & Total & \% \\
\hline Positive & 23 & $29 \%$ \\
\hline Negative & 57 & $71 \%$ \\
\hline Total & $\mathbf{8 0}$ & $\mathbf{1 0 0 \%}$ \\
\hline
\end{tabular}

Table.2 Gender distribution

\begin{tabular}{|c|c|c|}
\hline Cases & Males & Females \\
\hline No of cases & 46 & 34 \\
\hline No of RV positive cases & 12 & 11 \\
\hline
\end{tabular}




\begin{tabular}{|c|c|c|}
\hline \% of RV positive cases & $26 \%$ & $32 \%$ \\
\hline \% of total no. of positive cases & $15 \%$ & $14 \%$ \\
\hline
\end{tabular}

Table.3 Age distribution

\begin{tabular}{|c|c|c|c|c|}
\hline Group & Age in months & No. of cases & $\begin{array}{c}\text { No. of RV } \\
\text { positive cases }\end{array}$ & $\begin{array}{c}\text { \% of RV positive } \\
\text { cases for particular } \\
\text { Age group }\end{array}$ \\
\hline Group 1 & Less Than 2 years & 57 & 20 & $35 \%$ \\
\hline Group 2 & $\begin{array}{c}\text { Older Than 2 } \\
\text { years }\end{array}$ & 23 & 3 & $13 \%$ \\
\hline & Total & $\mathbf{8 0}$ & $\mathbf{2 3}$ & $\mathbf{2 9 \%}$ \\
\hline
\end{tabular}

Table.4 Prevalence of clinical symptoms

\begin{tabular}{|l|c|c|c|}
\hline Symptoms & No. of Cases & $\begin{array}{c}\text { No. of RV } \\
\text { positive cases }\end{array}$ & $\begin{array}{c}\% \text { RV positive } \\
\text { Cases }\end{array}$ \\
\hline Diarrhea & 80 & 23 & $29 \%$ \\
\hline Vomiting & 51 & 19 & $37 \%$ \\
\hline Fever & 53 & 19 & $36 \%$ \\
\hline$\downarrow$ Urine Output & 3 & 3 & $100 \%$ \\
\hline Abdominal pain & 4 & 2 & $50 \%$ \\
\hline Septicemia & 2 & 0 & $0 \%$ \\
\hline Shock & 1 & 0 & $0 \%$ \\
\hline Respiratory infections & 2 & 0 & $0 \%$ \\
\hline
\end{tabular}

Table.5 Prevalence of bacterial infection

\begin{tabular}{|l|l|}
\hline & No. Bacterial isolates \\
\hline RV positive & 2 \\
\hline RV negative & 12 \\
\hline Total & 14 \\
\hline
\end{tabular}

Chart.1 Seasonal distribution 


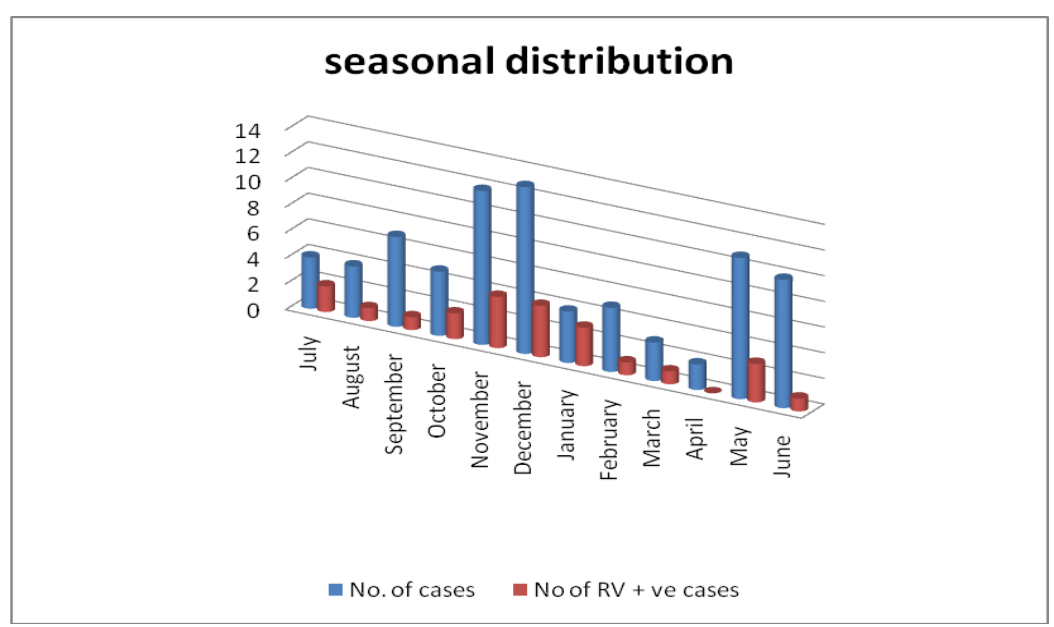

Abdominal pains were present in $8 \%$ of $\mathrm{RV}$ positive cases, but the prevalence rate was about 50\%. Chavan et al., 2013 and Shetty et al., 2014 stated that diarrhea and vomiting were predominant symptoms in RVGE. This study highlights the prevalence of Rota Viral Gastro Enteritis (RVGE) in under five year children which is $29 \%$. ELISA for detection of rotaviral antigen is the very usual method for early diagnosis of RVGE. This is the First study using Rota antigen ELISA test for Serological diagnosis of rotavirus in Thanjavur medical college and hospital for 80 samples.This study was done to determine the etiological factors for acute diarrhoea in children less than five years in tertiary hospital, Thanjavur. More than $80 \%$ of RVGE cases were under two years of age. Prevalence of Rotavirus diarrhoea in this study was about $29 \%$. Rotavirus diarrhoea was more common in the age group of below 2 years. There was no significant difference between the sexes in this study. Rotavirus diarrhoea was common during winter months from October to March. $87 \%$ of RV positive children presented with vomiting which was considered as second predominant symptom next to diarrhoea. 58\% of the cases reported with severe dehydration in this study. Duration of hospitalization in Rotavirus positive cases was more when compared to negative cases which imply severity of rotaviral infections. Out of 80 samples, 29\% were positive by ELISA. Rapid diagnostic procedures like Rota antigen detection by ELISA provides usual information to the physician, may prevent inappropriate treatment and nosocomial infections by intervening the spread of the infections in hospital set up.

\section{Acknowledgement}

We thank everyone who helped us in data collection. We also thank all the children and their parent/guardian who participated in this study.

\section{References}

Alrifai S.B., Alsaadi A., Mahmood Y.A., Ali A.A., Al-Kaisi L.A., 2009. Prevalence and etiology of nosocomial diarrhoea in children $<5$ years in Tikrit teaching hospital. Eastern Mediterranean Health Journal, 15(5), 1111-1118.

Ashwin Borade., 2010. Characteristics of rotavirus gastroenteritis in hospitalized children in pune. Indian Journal of Medical Sciences, 64, 210-218.

Ball, J. M., Tian P., Zeng C. Q., Morris A. P., and Estes M. K., 1996. Age-Dependent Diarrhea Induced by a Rotaviral Nonstructural Glycoprotein. Science magazine, 272(5258), 101-104.

Chavan, C., 2013. Prevalence of rotavirus diarrhoea among children hospitalized in a tertiary care hospital in Western India. Int J Pharm Biomed Sci. 4(1), 4- 
7.

Estes, M. K., and Cohen, J. 1989. Rotavirus gene structure and function. Microbiol Rev., 53(4): 410-449.

Kuruqol, Z. 2003. Rotavirus gastroenteritis among children under five of age in Izmir, Turkey. Turkey $\mathrm{J}$ pediatrics. 45(4), 290-294.

Manohar, B, Naramalli, M.L., Panabaka, R.K., Shankar, R.D., Shabbir A.S., Gagandeep, K., Cheri, N.K., 2015. Prevalence of Rotavirus diarrhea among under-5 hospitalized children in a Government Tertiary Hospital, Tirupati. Journal of Dr. NTR University of Health Sciences, 4(2), 112-116.

Obert G., Peiffer I., Servin A.L., 2000. Rotavirus-Induced Structural and Functional Alterations in Tight Junctions of Polarized Intestinal Caco-2 Cell Monolayers. J. VIROL., 74(10), 4645-4651.

Salim A.F., Phillips A.D., Walker-Smith J.A., Farthing M.J.G., 1995. Sequential changes in small intestinal structure and function during rotavirus infection in neonatal rats. Gut., 36, 231-238.
Shetty A.K., Kalekhan, F.M., Muthiravalapil, S.J., Boloor, R., Antony, B., 2014. Rotavirus and Adenovirus diarrhea in children. Muller Journal of Medical Science and Research, 5(2), 143-148.

Stintzing G, Johansen K, Magnusson KE, Svensson L, Sundqvist T, 1986. Intestinal permeability in small children during and after rotavirus diarrhoea assessed with different-size polyethyleneglycols (PEG 400 and PEG 1000). Acta Paediatr Scand., 5(6), 10059.

WHO/UNICEF Joint statement. Clinical management of acute diarrhea. Geneva, Switzerland: WHO publications; 2004 May.8 p. Report No.: WHO/FCH/CAH/04.7 or UNICEF/PD/ Diarrhoea/01

Xiaoli L. Pang, et al. (2004) Increased detection of rotavirus using a real time reverse transcription-polymerase chain reaction (RT-PCR) assay in stool specimens from children with diarrhea. Journal medical virology. 72(3/mar). Pp. 496-501.

\section{How to cite this article:}

Shanthi, A. and Bhuvaneshwari, C.K. 2019. Study on Prevalence of Diarrhea among Children with Special Reference to Rotavirus in Thanjavur, Tamilnadu. Int.J.Curr.Microbiol.App.Sci. 8(03): 1030-1036. doi: https://doi.org/10.20546/ijcmas.2019.803.125 